\title{
EFFICIENT FUNCTIONALIZATION OF CARBON NANOHORNS VIA MICROWAVE IRRADIATION
}

\author{
Ester Vázquez, ${ }^{a}$ Maurizio Prato, ${ }^{b}$ Noelia Rubio, ${ }^{a}$ M. Antonia Herrero, ${ }^{a}$ Moreno Meneghetti ${ }^{c}$ \\ ${ }^{a}$ Departamento de Química Orgánica, Facultad de Química, Universidad de Castilla-La \\ Mancha, 13071 Ciudad Real, Spain. ${ }^{b}$ Dipartimento di Scienze Farmaceutiche, Università \\ degli Studi di Trieste, Piazzale Europa 1, 34127 Trieste, Italy. ${ }^{c}$ Dipartimento di Scienze \\ Chimiche, Università di Padova, Via Marzolo 1, 35131 Padova, Italy. \\ ester.vazquez@uclm.es
}

The mass production of new carbon nanostructures and their potential applications in many different fields have made these materials the subject of heavy investigations. ${ }^{1}$ Carbon Nanohorns (CNHs) ${ }^{2}$ represent a new type of nanostructured carbon-based material, which possess interesting properties for applications in clean-energy technologies as well as biology and medicine. ${ }^{3}$ A primary $\mathrm{CNH}$ particle is a single graphene tube (similar in structure to single-walled carbon nanotubes) with $2-5 \mathrm{~nm}$ in diameter and a length of 40-50 nm, with a conically-closed tip. Around $2000 \mathrm{CNHs}$ aggregate with each other to form a spherical dahlia flower-like structure with a rather narrow diameter distribution of 80-100 nm (figure1). The high purity of produced CNHs is their major advantage as compared to carbon nanotubes, they are completely metal-free. Functionalization of CNHs has given scientists the ability to manipulate these structures enhancing their solubility and broadening the spectrum of applications. While different covalent functionalization strategies have been described, ${ }^{4}$ reactions usually proceed with long times, in the presence of highly contaminating solvents and/or under harsh conditions.

In the present work, we explore the efficiency of microwave irradiation for the covalent functionalization of CNHs. Two different reactions have been used, the 1,3-dipolar cycloaddition of azomethine ylides, in solvent-free conditions and the addition of diazonium salts in water, both functionalization methods allow the preparation of $\mathrm{CNH}$ derivatives with many functionalities. As a result of the covalent attachments onto the skeleton of CNHs the solubility is highly enhanced in several common organic solvents as well as in water. The differences observed are highly dependent on the polarity and the number of groups covalently attached to the CNHs. (Figure 2).

In addition, a combination of the two reactions has also permitted the preparation of doubly functionalized CNHs with orthogonally protected groups (figure 3). These groups, in principle, can be selectively cleaved and modified with different moieties, broadening the number of derivatives that can be prepared and paving the way to new applications. Finally, the microwave-assisted organic transformations here described proceed with short reaction times and involve two benign alternatives, namely solvent-free or aqueous reaction media.

\section{References:}

[1] J. Mater. Chem, 18 (2008) 1401-1604, Special Issue on Carbon Nanostructures, D. Guldi, N. Martin, M. Prato, Eds.

[2] S. Iijima, M. Yudasaka, R. Yamada, S. Bandow, K. Suenega, F. Kokai, K. Takahashi, Chem. Phys. Lett., 309 (1999)165.

[3] a) K. Murata, K. Kaneko, H. Kanoh, D. Kasuya, K. Takahashi, F. Kokai, M. Yudasaka, S. Iijima. J. Phys. Chem., B, 106 (2002) 1132. b) K. Murata, A. Hashimoto M. Yudasaka, D. Kasuya, K. Kaneko S. Iijima, Adv. Mater., 16 (2004) 1520. c) K. Ajima, M. Yudasaka, T. 
Murakami, A. Maigne, K. Shiba, S. Iijima, Mol. Pharm., 2 (2005) 475. d) H. Isobe, T. Tanaka, R. Maeda, E. Noiri, N. Solin, M. Yudasaka, S. Iijima, E. Nakamura. Angew. Chem. Int. Ed., 45 (2006) 6676. e) S. Lacotte, A. García, M. Décossas, W. T. Al-Jamal, S. Li, K. Kostarelos, S. Muller, M. Prato, H. Dumortier, A. Bianco, Adv. Mater., 20 (2008) 2421.

[4] a) N. Tagmatarchis, A. Maigne, M. Yudasaka, S. Iijima, Small, 2 (2006) 490. b) C. Cioffi, S. Campidelli, F.G. Brunetti, M. Meneghetti, M. Prato, Chem. Commun., (2006) 2129. c) C. Cioffi, S. Campidelli, C. Sooambar, M. Marcaccio, G. Marcolongo, M. Meneghetti, D. Paolucci, F. Paolucci, C. Elhi, G. M. Rahman, V. Sogobba, D. M. Guldi, M. Prato, J. Am. Chem. Soc., 129 (2007) 3938. d) G. Pagona, N. Karousis, N. Tagmatarchis, Carbon, 46 (2008) 604.

\section{Figures:}

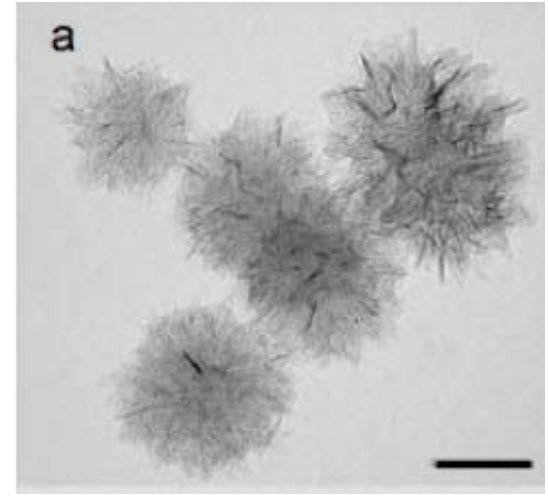

Figure 1

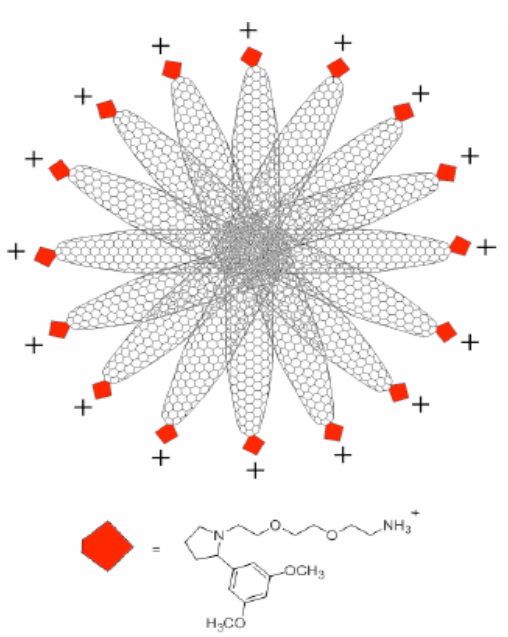

Figure 2

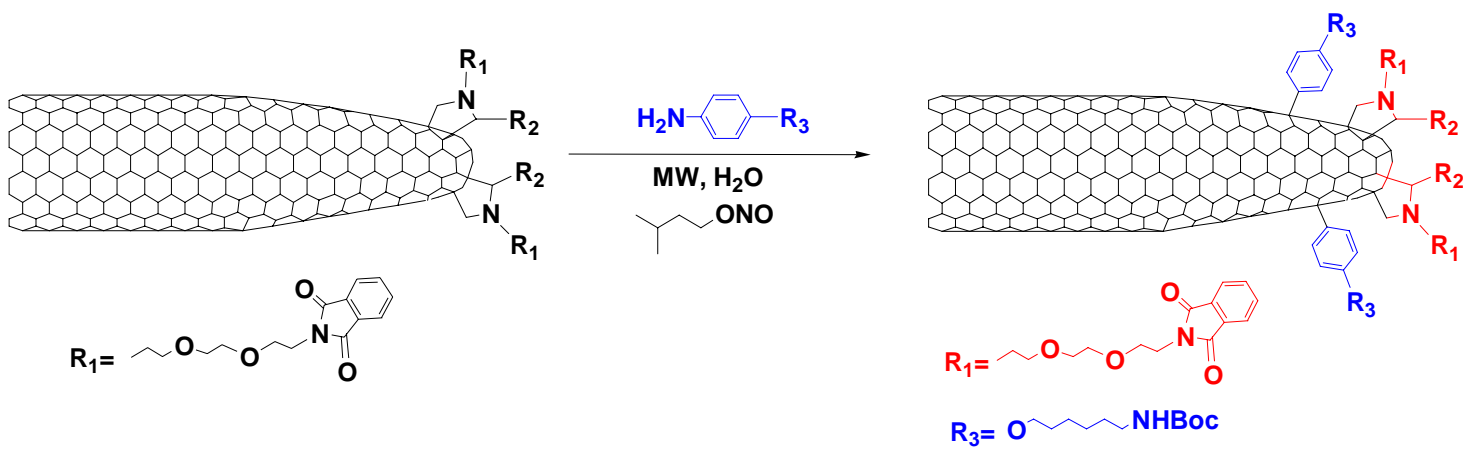

Figure 3 